\title{
The identification and management of substance use disorders in anesthesiologists
}

\section{L'identification et la prise en charge des troubles de consommation de substances chez les anesthésiologistes}

\author{
Lisa G. Lefebvre, MDCM, MPH • I. Michael Kaufmann, MD
}

Received: 25 July 2016/Revised: 3 October 2016/Accepted: 8 November 2016/Published online: 29 November 2016

(C) Canadian Anesthesiologists' Society 2016

\begin{abstract}
Purpose The purpose of this article is to review current evidence for the identification and management of substance use disorders in anesthesiologists and to describe an approach to return to practice.

Principal findings Anesthesiologists experience substance use disorders at a rate reported to be 2.7 times that of other physicians. Effective evidence-based treatment is available for physicians with substance use disorders, including anesthesiologists. Significant barriers preventing access to such treatment still exist, some of which are specific to the physician cohort. Standard of care should involve ongoing monitoring of substance use disorders in a chronic disease management paradigm. The outcomes for anesthesiologists treated and monitored for a substance use disorder are similar to those for other physicians and significantly superior to those for the general population. Return to work is possible and is most effectively managed in an occupational health risk management model.

Conclusion The treatment of substance use disorders in anesthesiologists is effective, and a safe return to practice is possible in a majority of cases. National guidelines are needed to ensure equitable access to high-quality treatment and recovery monitoring for all Canadian physicians.
\end{abstract}

\section{Résumé}

Objectif L'objectif de cet article est de passer en revue les données probantes actuelles concernant l'identification et la prise en charge des troubles de consommation de substances chez les anesthésiologistes, et de décrire une

L. G. Lefebvre, MDCM, MPH (ه) - I. M. Kaufmann, MD Ontario Medical Association Physician Health Program, Suite 900, 150 Bloor Street West, Toronto, ON M5S 3C1, Canada e-mail: Lisa.Lefebvre@oma.org approche envisageable pour favoriser un retour à la pratique.

Constatations principales Les anesthésiologistes sont victimes de troubles de consommation de substances à un taux rapporté qui est 2,7 fois plus élevé que les autres médecins. Un traitement efficace et fondé sur des données probantes est disponible pour les médecins - y compris les anesthésiologistes - souffrant de troubles de consommation de substances. Toutefois, d'importants obstacles existent encore et entravent l'accès à un tel traitement, dont certains sont spécifiques aux médecins. La norme de soins devrait comporter une surveillance constante des troubles de consommation de substances dans le cadre d'un paradigme de prise en charge de maladie chronique. Les dénouements pour les anesthésiologistes traités et supervisés pour un trouble de consommation de substances sont semblables à ceux des autres spécialités et significativement supérieurs à ceux observés dans le grand public. Un retour au travail est donc possible; la façon la plus efficace de prendre en charge ce retour au travail est d'appliquer un modèle de gestion du risque pour la santé au travail.

Conclusion Le traitement des troubles de consommation de substances chez les anesthésiologistes est efficace et, dans la majorité des cas, un retour sécuritaire à la pratique est possible. Des directives nationales sont nécessaires afin de garantir un accès équitable à un traitement de qualité élevée ainsi qu'à une supervision du rétablissement pour tous les médecins canadiens.

The Canadian Society of Addiction Medicine has adopted the following definition of addiction: "Addiction is a primary, chronic disease of brain reward, motivation, memory and related circuitry. Dysfunction in these circuits leads to characteristic biological, psychological, social and spiritual manifestations. This is reflected in an individual pathologically pursuing reward and/or relief by substance 
Table 1 DSM-5 diagnostic criteria for substance use disorder

\begin{tabular}{|c|c|}
\hline $\begin{array}{l}\text { DSM-5 substance use } \\
\text { disorder }\end{array}$ & Diagnostic criteria \\
\hline $\begin{array}{l}\text { Severity based on number } \\
\text { of criteria: } \\
\text { 2-3: Mild } \\
\text { 4-5: Moderate } \\
\geq 6 \text { : Severe } \\
\text { *criteria do not apply to } \\
\text { prescribed medications }\end{array}$ & $\begin{array}{l}\text { - At least } 2 \text { of the following occurring } \\
\text { within a } 12 \text {-month period: } \\
\text { - Substance taken in larger amounts or } \\
\text { over a longer period than intended } \\
\text { - Persistent or unsuccessful efforts to } \\
\text { control substance use } \\
\text { - Significant time spent on substance- } \\
\text { related activities } \\
\text { - Craving } \\
\text { - Recurrent use results in failure to } \\
\text { fulfill major life obligations } \\
\text { - Continued substance use despite } \\
\text { interpersonal and/or social problems } \\
\text { - Continued substance use despite } \\
\text { physical and/or psychological } \\
\text { problems } \\
\text { - Important activities are given up or } \\
\text { reduced because of substance use } \\
\text { - Recurrent use in situations in which it } \\
\text { is physically dangerous } \\
\text { - Tolerance* } \\
\text { - Withdrawal* }\end{array}$ \\
\hline
\end{tabular}

DSM = Diagnostic and Statistical Manual of Mental Disorders

use and other behaviours." ${ }^{1}$ A major change occurred with respect to substance use disorders in the revision of the Diagnostic and Statistical Manual of Mental Disorders (DSM)-IV to the DSM-5. In the DSM-5, the previously separate diagnoses of substance abuse and substance dependence were combined to establish the term substance use disorder, a single diagnostic entity spanning a continuum from mild to severe (Table 1). ${ }^{2}$ In this present paper, the terms addiction and moderate-tosevere substance use disorder are treated as equivalent.

The current approach to the identification and treatment of physicians with substance use disorders has its roots in the 1970s. At that time, the understanding of addiction as a disease began to replace that of addiction as vice. With the dawn of this new understanding, novel treatment programs were developed, and the approach to individuals with addiction became more therapeutic and less punitive. While much progress was made over the subsequent decades -with significant advances in the understanding of the neurobiological processes underlying the behavioural manifestations of addiction ${ }^{3}$ - stigma still remains. Volkow et al. comment that "A more comprehensive understanding of the brain disease model of addiction may help to moderate some of the moral judgment attached to addictive behaviors and foster more scientific and public health-oriented approaches to prevention and treatment." $\mathrm{A}$ focus on the development of evidence-based treatments for addiction has led to new approaches in both psychosocial and pharmacological therapy.

In this narrative review, we discuss an approach to the identification and management of substance use disorders in anesthesiologists with a focus on the moderate-to-severe spectrum.

\section{Epidemiology}

The prevalence of substance use disorders in physicians is approximately the same as that in the general population. Two recent surveys of American physicians found that $15 \%$ of respondents screened positive for alcohol use disorder, ${ }^{5,6}$ which is slightly higher than the results of previous studies. $^{7-9}$ In a 2008 study of a cohort of physicians treated for substance use disorders, family medicine, internal medicine, anesthesiology, emergency medicine, and psychiatry accounted for more than $50 \%$ of the physicians treated, with anesthesiologists accounting for $10.9 \%{ }^{10}$ The most commonly reported primary substances for the entire cohort in this study were alcohol $(50 \%)$, opiates $(36 \%)$, and stimulants $(8 \%)$, with $13.9 \%$ of respondents reporting a history of intravenous drug use. Certain specialty-specific patterns of substance use have been noted. In a sub-analysis of the anesthesiologists in this cohort, the most commonly reported primary substance was opioids (55\%), followed by alcohol $(28 \%)$ and stimulants $(8 \%)$, with a much higher proportion $(41 \%)$ reporting a history of intravenous drug use. Among the opioids used by anesthesiologists, sufentanil and fentanyl topped the list, suggesting access is an important risk factor. ${ }^{11,12}$ A recent Canadian study replicated these findings, noting that opioids, and fentanyl in particular, were the substances most commonly used by anesthesiologists. ${ }^{13}$

The risk of a drug-related death for anesthesiologists has been reported to be nearly three times that for internal medicine physicians. ${ }^{14} \mathrm{~A}$ recent matched cohort analysis of anesthesiology residents found that those with a substance use disorder had a $14.1 \%$ mortality rate $v s 1.3 \%$ in matched controls. ${ }^{15}$ In another analysis of the same cohort, the rate of substance use disorders in anesthesiology residents decreased during 1996-2002 when compared with 19752001. Subsequently, however, the rate reached its highest level during 2003-2009, indicating a persistent problem. ${ }^{16}$ Anesthesiologists are also consistently overrepresented in both treatment and physician health programs, ${ }^{7,17,18}$ and their risk of addiction has been calculated to be 2.7 times that of other physicians. ${ }^{19}$ 
Table 2 Warning signs that may indicate a substance use disorder in a physician

Warning signs that may indicate a substance use disorder ${ }^{22}$

- frequent mood swings

- irritability

- anger

- withdrawal from social activities

- weight loss

- volunteering for extra work

- preferring to work alone

- spending time in hospital when off duty

- refusing relief for meals

- extra bathroom breaks

- signing out increasing amounts of narcotics compared with colleagues and one's own usual practice (particularly before days off)

- unexplained absences

\section{Management}

As with any other disease, the management of substance use disorders in both physicians and the general population should adhere to an algorithm with which all physicians are familiar, i.e., identification, diagnosis, treatment, and follow-up.

\section{Identification}

The identification of a substance use disorder is often challenging in the general population due significant barriers to self-disclosure, including stigma, shame, and fear of judgement. This is further magnified in the physician population by fear of repercussions with respect to licensure and employment. Additional occupation-specific barriers to identification of substance use disorders in physicians also exist. Physicians often have direct access to substances of abuse and do not need access through a "supplier". They know the signs and symptoms of addiction and are better able to hide them, and they are psychologically capable of developing sophisticated denial strategies. $^{20}$ In addition, physicians receive little training in the identification and management of substance use disorders and are often hesitant to report potentially impaired colleagues due to fear of negative consequences. $^{21}$ Therefore, it is difficult for ill physicians to reach out for help spontaneously, and they frequently need assistance from others around them to seek appropriate evaluation and treatment. Consequently, all physicians must be vigilant for warning signs indicating that a colleague may suffer from a substance use disorder, and they must also be prepared to provide assistance in such instances.
The most ubiquitous warning sign is a significant change in an individual's level of function from a previously established baseline. Other warning signs are summarized in Table 2. ${ }^{22}$ Behaviours more specific to anesthesia include removing contents of syringes or ampules and replacing them with saline (confirmed via forensic testing of the contents), charting a case as opioid-based while using only inhalational agents and $\beta$-blockers, and diversion of wasted narcotics from sharps containers. Vigilance for such warning signs is critical, as early intervention will serve to prevent harm to both the physicians and their patients. Despite this, colleagues may still attempt to find other potential explanations for behaviours that are typically associated with substance use problems. Unfortunately, despite a shared duty to protect patients, there is still a misperception that helping or reporting a colleague may do more harm than good.

\section{Diagnosis}

Once a physician with a suspected substance use disorder is identified, referral to a specialist in addiction medicine or addiction psychiatry for a comprehensive biopsychosocial evaluation is critical in order to develop an individualized treatment plan. Several different organizations certify physician competence in this area. Physicians may be recognized by the Royal College of Physicians and Surgeons of Canada as having an Area of Focused Competence (Diploma) in Addiction Medicine, or they may be accredited in future by the College of Family Physicians of Canada, which is developing a Certificate of Added Competence in Addiction Medicine. They may also be recognized by the American Board of Addiction Medicine and/or by the American Board of Psychiatry and Neurology as subspecialists in addiction psychiatry. The Canadian Society of Addiction Medicine and the International Society of Addiction Medicine also certify physicians as experts in addiction medicine. Such physicians may be accessed through provincial physician health programs (https://www.cma.ca/En/pages/provincialphysician-health-programs.aspx) and, where these do not exist, the provincial regulatory body.

An evaluation for a substance use disorder should include a complete history (psychiatric, substance use/ process addictions, medical, family, developmental, social, legal, educational, occupational, and other components as indicated), collection of collateral information in written form (e.g., prior charts or records), collateral information collected verbally from third parties (e.g., treating professionals, family members, colleagues), physical examination, mental status examination, and laboratory or other testing (e.g., toxicology, neurocognitive, or other 
psychological testing). Collection of collateral information from individuals who know the physician both in and out of the workplace is essential. The collection of out-ofworkplace perspectives is vital, as the workplace is often the last place in which signs and symptoms of addiction are displayed. $^{23}$ Evaluators should be asked to provide diagnostic formulations referencing DSM-5 criteria. It is critical that evaluators carefully consider the possibility of a substance use disorder and/or other concurrent psychiatric disorders in order to plan appropriate treatment. Standardized diagnostic instruments, e.g., the AUDIT (Alcohol Use Disorders Identification Test - http:// pubs.niaaa.nih.gov/publications/Audit.pdf) and others are frequently used in such evaluations.

\section{Treatment}

Medicine, by definition, is a safety-sensitive occupation given its responsibility to the public and the magnitude and gravity of the potential effects of physician impairment. Recommendations from a formal evaluation must guide treatment, and such management should address the issues unique to physicians with substance use and other psychiatric disorders. Currently, there is a lack of consensus on how best to treat physicians with a mild substance use disorder. Some physician health programs, including that of the Ontario Medical Association, offer prospective monitoring for such individuals for two years in an attempt to rule out a more severe substance use disorder.

The treatment paradigm for a physician with a moderate-to-severe substance use disorder is well established, and it consists of total abstinence from all substances, including alcohol, if the physician plans to return to the practice of medicine. The initial intensive treatment for a physician with a newly diagnosed substance use disorder frequently occurs in an inpatient setting and includes supervised medical detoxification (if indicated) at the treatment centre or prior to treatment entry. The inpatient setting allows the individual to achieve early stable remission more rapidly than in an outpatient setting, although intensive outpatient treatment may also be considered. Treatment programs typically combine individuals whose substances of abuse differ from each other (e.g., opioid, alcohol, and stimulant use disorders). Patients may be treated together once detoxified, as the basic principles of treatment are the same for all substances. Importantly, physicians should not be working in any capacity during intensive treatment, whether the treatment is for an initial episode or following a relapse.

In determining the success of primary treatment, regardless of the setting, it is critical to obtain an objective assessment of an individual's ability to attain key treatment goals. Such goals include a) understanding and acceptance of the chronic disease model for moderateto-severe substance use disorders, b) understanding the rationale for total abstinence and agreement with that goal, c) acquiring the fundamental skills to prevent a relapse, d) having been facilitated to a trial of group recovery approaches, such as peer support, 12-step or other models, and e) appreciating the accountability required as a safety-sensitive worker in a self-regulated profession and how monitoring can facilitate such accountability.

Placement criteria developed by the American Society of Addiction Medicine ${ }^{23}$ recommend cohort-specific treatment for physicians. A cohort-specific environment creates the psychological safety necessary to promote selfdisclosure, which is essential in the treatment process. The shame experienced by many individuals with a substance use disorder may constitute a barrier to treatment entry or interfere with progress in treatment. This barrier may be even more significant for healthcare professionals as shame is closely intertwined with professional identity. Support from peers during the treatment experience helps individuals learn to address and overcome shame. Staff must be trained to avoid reactive judgement in order to create a safe environment that encourages this type of healing. In addition, physicians frequently need to navigate a successful return to work in an environment in which they may be exposed to their previous substance of choice. Cohort-specific treatment promotes acquiring drug refusal skills while addressing drug access and modification of the work environment. In addition, healthcare professionals commonly have difficulty assuming the role of patient. This problem can be specifically addressed when treatment occurs in a peer group. Such an environment also prevents the physician-patient from taking on the role of treatment professional when interacting with layperson group members. Finally, treatment staff should be familiar with substances typically used by the cohort as well as the work environment of the safety-sensitive professional, including related political, legal, and regulatory issues. Treatment providers should be aware of any available monitoring programs and help the physician understand that ongoing monitoring is an integral part of follow-up care and accountability to the public.

While pharmacotherapy, such as methadone and buprenorphine maintenance, is commonly used to treat opioid use disorder in the general population, its use in healthcare professionals has not been studied and remains controversial. ${ }^{24}$ Advocates for the use of such therapies state that the lack of evidence should not preclude healthcare professionals from accessing a treatment that has become part of the standard of care for opioid use disorders. ${ }^{25}$ Others point to the cognitive dysfunction 
shown in studies of the general population, extrapolating that these findings could be clinically relevant in a safetysensitive profession and suggesting that a cautious approach is best until more evidence is available. ${ }^{26}$ This view applies to the ongoing use of these medications in a maintenance paradigm but does not preclude their use for detoxification in a supervised inpatient treatment setting. There is general consensus, however, that long-term use of benzodiazepines should generally be avoided in safetysensitive populations due to a significant risk of cognitive impairment.

Naltrexone is an opioid receptor antagonist used in the treatment of health professionals with opioid use disorder to prevent relapse. ${ }^{27}$ The drug has no cognitive side effects and is particularly useful in physicians who are returning to a work setting in which they are exposed to opioids. In Canada, the monthly intramuscular depot preparation of naltrexone is not yet available; therefore, only the oral form can be prescribed, preferably with witnessed ingestion to ensure compliance. Naltrexone is also indicated for the treatment of alcohol use disorder, as is acamprosate; however, very few patients with alcohol use disorder receive such treatments, ${ }^{28}$ and our anecdotal experience indicates that physicians are no different in this regard. Given the demonstrated efficacy and lack of cognitive side effects of these two medications, it stands to reason that they should be used more frequently in physicians.

\section{Follow-up}

Follow-up for a physician with a substance use disorder should adhere to the principles of chronic disease management. Frequent visits with an addiction medicine physician or addiction psychiatrist are crucial upon discharge from intensive treatment and should continue for the long term at a diminishing frequency consistent with clinical progress. As with the general population of patients diagnosed with a substance use disorder, aftercare is typically offered in a group treatment setting (at the same facility where the initial treatment occurred or in the physician's local community) for six to 12 months. The physician-patient should obtain a family physician to avoid self-treatment, which often co-occurs with a substance use disorder. Attendance at support groups facilitated for health professionals or "caduceus" groups provides a mixture of encouragement and accountability from peers with lived experience. Other care providers, such as therapists and coaches, should form part of the follow-up treatment team along with the addiction physician, family physician, and caduceus group leader.

Communication between the members of the follow-up team is paramount for early detection and treatment of any relapse. A relapse is defined as any use of an unauthorized substance. Pre-existing non-modifiable risk factors for relapse include prior relapse following an earlier treatment episode, a concurrent psychiatric disorder, and family history of a substance use disorder. ${ }^{29}$ Modifiable risk factors include adherence to the treatment plan as well as support from family, friends, and the workplace. Use of a major opioid (e.g., fentanyl, sufentanil, morphine, meperidine, methadone, heroin, and/or oxycodone) further increases the risk of relapse for individuals with a family history and/or a concurrent psychiatric disorder. ${ }^{29}$ Not surprisingly, anesthesiologists who returned to the practice of anesthesiology had a significantly higher risk of relapse than those who did not. While the likelihood of relapse decreased as time in a monitoring program increased, the risk of a future relapse increased with each relapse. Therefore, it is critically important for providers of ongoing follow-up care to assess and intervene when action is necessary to delay or prohibit a safety-sensitive worker from returning to work. ${ }^{23}$

\section{Physician health programs}

In tandem with the emergence of the new paradigm framing addiction as a disease and not a vice, groups of physicians began to organize themselves to help the "impaired physician". ${ }^{20}$ These groups evolved over time into what are now known as physician health programs (PHPs), devoted to "the twin goals of protecting the public and saving the lives and careers of addicted physicians". Confidentiality was critical as the high level of stigma related to addiction in the general population was heightened with respect to health professionals. Physician health programs were created recognizing the need for careful balance between participant confidentiality and the required accountability of a safety-sensitive profession.

One of the primary guiding principles of PHPs is that most physicians with a psychiatric or substance use disorder can safely return to practice with careful risk management that considers the perspectives of all relevant stakeholders. Physician health programs vary in size and structure depending on geographical location, but most are able to assist in all aspects of support for an impaired physician. The Federation of State Physician Health Programs is a North American organization developed to "support Physician Health Programs in improving the health of medical professionals, thereby contributing to quality patient care." ${ }^{30}$ Critical to the success of any PHP is gaining the trust of the local regulatory body. This allows the PHP to guide treatment and monitoring in lieu of disciplinary sanctions, with the stipulation that failure to comply with PHP recommendations would result in referral back to the regulatory body. The rigour of the PHP model also allows for advocacy on behalf of participants to third parties such as hospitals, academic institutions, and insurance companies, among others. 
A recent study of the PHP model revealed that $78 \%$ of those who completed treatment and five years of monitoring did not have a single detected relapse over those five years. ${ }^{20}$ This rate of sustained success is much greater than the success rate of $40-60 \%$ for standard addiction treatment in the general population ${ }^{10}$ where much shorter follow-up intervals were studied. A prospective study conducted by the Ontario Medical Association Physician Health Program reported that $85 \%$ of physicians successfully completed fiveyear monitoring for a moderate-to-severe substance use disorder, with $71 \%$ having no detected relapse. ${ }^{31}$ The PHP model utilizes individualized evaluation and treatment as described above, coupled with intensive monitoring of toxicology and treatment compliance in a contingency management paradigm. Other successful examples of the contingency management model include drug treatment courts where offenders with an addiction are diverted to treatment with outcomes superior to standard addiction treatment. In such cases, non-compliance results in immediate incarceration. ${ }^{32}$

Physician health programs respond to relapse by sending physicians for re-evaluation, increasing the intensity of monitoring, and bolstering follow-up treatment. ${ }^{20}$ Depending on the severity of the relapse, a report may be forwarded to the regulatory authority, which may then impose sanctions such as limited practice or restricted access to controlled substances. Furthermore, a PHP has the ability to request a monitored physician to cease practice temporarily following a relapse until a safe return can be planned and executed. The PHP can report non-compliance with such a request to the regulatory authority. In one study of a cohort of physicians from 16 PHPs, 95\% of those who completed their monitoring contracts were still licensed and less than $1 \%$ had died. At the same time, only $21 \%$ of physicians who did not complete their contract were still licensed and $17 \%$ had died. ${ }^{10}$ In a sub-analysis of the anesthesiologists in this cohort, there was no significant difference in the proportion continuing practice compared with other physicians and no patient harm was detected. ${ }^{33}$ Anesthesiologists received similar treatment and monitoring as other physicians along with several additional components, including frequent prescribing of naltrexone, hair testing (more effective at detecting fentanyl than urine testing and less prone to tampering), and enhanced precautions in the operating room to prevent diversion.

\section{Return to work}

The return of anesthesiologists in recovery from a substance use disorder to the operating room is not without controversy. ${ }^{34}$ Nevertheless, much of the evidence driving the concern is of poor quality and does not consider the outcomes reported in studies of the rigorous PHP model. ${ }^{11,19}$ In the PHP model, an individualized and carefully managed return-to-work plan is integrated seamlessly into formal recovery monitoring. Collaboration amongst all parties (physician, PHP, treatment providers, workplace) is critical in order to identify and mitigate risk proactively -for patients, recovering physicians, and the workplace. The return-towork process must be carefully planned and monitored so that occupational activities that carry more risk can be added progressively in a staged manner. This process must take into account inherent risk factors in the recovering individual (e.g., workload, night call) as well as in the work environment (e.g., narcotic access, high-risk procedural work). This process is of particular relevance to higher risk specialities, such as anesthesiology, which are highly safety-sensitive and where access to controlled substances must be carefully managed. Despite the approach described above, there may be some instances where an anesthesiologist may elect not to return to work in the operating room environment or where it is deemed to be illadvised. Such occasions would include lack of confidence on the part of the anesthesiologist, non-adherence to the treatment plan, lack of support from the workplace, and/or poor psychosocial support.

\section{Future directions}

Historically, the anesthesia community has recognized addiction as an occupational risk with particular relevance to the specialty. As such, anesthesia has led the way in developing education for physicians on this topic. Other interventions, such as forensic narcotic audits and urine drug testing, have been proposed by some, and these suggestions warrant further exploration along with other novel approaches. Much variability exists across Canada with respect to the management of substance use disorders in anesthesiologists as well as the handling of narcotics in the operating room. ${ }^{13}$ The anesthesia community could take further leadership by working with academic departments, residency programs, and specialty societies to develop formal policies and procedures to guide an occupational health approach to substance use disorders among physicians in Canada.

\section{Conclusion}

Physicians experience substance use disorders at approximately the same rate as the general population, but the risk for anesthesiologists is reportedly 2.7 times that of other physicians. Given the significant barriers to selfdisclosure, it is important for colleagues to be prepared to intervene if concerns regarding substance use arise. A 
comprehensive evaluation is essential in order to diagnose a substance use disorder and to recommend appropriate treatment. Effective evidence-based treatment for physicians with such disorders does exist, and ongoing monitoring in a chronic disease management paradigm should be the standard of care. The outcomes for anesthesiologists treated and monitored for a substance use disorder are similar to those for other physicians and significantly superior to outcomes for the general population. Return to work is most effectively managed in an occupational health risk management model. Further development of national guidelines to outline a chronic disease management and occupational health approach to substance use disorders in anesthesiology and other medical specialties is needed to ensure equitable access to high-quality treatment and recovery monitoring for all Canadian physicians.

\section{Key points}

- Physicians experience substance use disorders at approximately the same rate as the general population, but the risk for anesthesiologists is reported to be 2.7 times that of other physicians.

- Significant barriers to self-disclosure exist, and it is important for colleagues to intervene if concerns arise.

- Effective evidence-based treatment for physicians with substance use disorders does exist.

- Ongoing monitoring of substance use disorders in a chronic disease management paradigm is the standard of care.

- Anesthesiologists have the same rate of success in recovery from substance use disorders as other physicians.

- National guidelines are needed to ensure equitable access to high-quality treatment and recovery monitoring for all Canadian physicians.

Acknowledgements We sincerely thank Karen Lee, Manager, Research and Environmental Scanning, Economics, Research \& Analytics, Ontario Medical Association, for her assistance with the literature review. We are also grateful to Pat Buczkowski, Coordinator, Research Centre, Economics, Research \& Analytics, Ontario Medical Association for her assistance in formatting the paper. Drs. Lefebvre and Kaufmann are employees of the Ontario Medical Association. They have no conflicts of interest or consultancies to declare.

Author contributions Drs. Lefebvre and Kaufmann contributed to the conception and design of the article. Dr. Lefebvre conducted the literature review and drafted the article. Both authors revised the article critically for important intellectual content.

Editorial responsibility This submission is handled by Dr. Gregory L. Bryson, Deputy Editor-in-Chief, Canadian Journal of Anesthesia.

\section{References}

1. Canadian Society of Addiction Medicine. Definition of Addiction. Calgary, AB: Canadian Society of Addiction Medicine; 2011. Available from URL: http://www.csam-smca.org/about/policystatements/ (accessed October 2016).

2. American Psychiatric Association. Diagnostic and Statistical Manual of Mental Disorders. 5th ed. Arlington, VA: American Psychiatric Association Publishing; 2013. p. 481-589.

3. MacNicol B. The biology of addiction. Can J Anesth 2017; 64 . DOI:10.1007/s12630-016-0771-2.

4. Volkow ND, Koob GF, McLellan AT. Neurobiologic advances from the brain disease model of addiction. N Engl J Med 2016; 374: 363-71.

5. Oreskovich MR, Kaups KL, Balch CM, et al. Prevalence of alcohol use disorders among American surgeons. Arch Surg 2012; 147: 168-74.

6. Oreskovich MR, Shanafelt T, Dyrbye $L N$, et al. The prevalence of substance use disorders in American physicians. Am J Addict 2015; 24: 30-8.

7. Paris RT, Canavan DI. Physician substance abuse impairment: anesthesiologists vs. other specialties. J Addict Dis 1999; 18: 1-7.

8. McAuliffe WE, Rohman M, Breer P, Wyshak $G$, Santangelo $S$, Magnuson E. Alcohol use and abuse in random samples of physicians and medical students. Am J Public Health 1991; 81: 177-82.

9. Hughes PH, Brandenburg N, Baldwin DC Jr, et al. Prevalence of substance use among US physicians. JAMA 1992; 267: 2333-9.

10. McLellan AT, Skipper GS, Campbell M, DuPont RL. Five year outcomes in a cohort study of physicians treated for substance use disorders in the United States. BMJ 2008; 337: a2038.

11. Oreskovich $M R$, Caldeiro RM. Anesthesiologists recovering from chemical dependency: can they safely return to the operating room? Mayo Clin Proc 2009; 84: 576-80.

12. Kintz $P$, Villain $M$, Dumestre $V$, Cirimele $V$. Evidence of addiction by anesthesiologists as documented by hair analysis. Forensic Sci Int 2005; 153: 81-4.

13. Boulis S, Khanduja PK, Downey K, Friedman Z. Substance abuse: a national survey of Canadian residency program directors and site chiefs at university-affiliated anesthesia departments. Can J Anesth 2015; 62: 964-71.

14. Alexander BH, Checkoway H, Nagahama SI, Domino KB. Causespecific mortality risks of anesthesiologists. Anesthesiology 2000; 93: 922-30.

15. Warner DO, Berge K, Sun H, Harman A, Hanson A, Schroeder DR. Risk and outcomes of substance use disorder among anesthesiology residents: a matched cohort analysis. Anesthesiology 2015; 123 : 929-36.

16. Warner DO, Berge K, Sun H, Harman A, Hanson A, Schroeder $D R$. Substance use disorder among anesthesiology residents, 1975-2009. JAMA 2013; 310: 2289-96.

17. Pelton C, Ikeda RM. The California Physicians Diversion Program's experience with recovering anesthesiologists. J Psychoactive Drugs 1991; 23: 427-31.

18. Talbott GD, Gallegos KV, Wilson PO, Porter TL. The Medical Association of Georgia's Impaired Physicians Program. Review of the first 1000 physicians: analysis of specialty. JAMA 1987; 257: 2927-30.

19. Skipper GE, Campbell MD, Dupont RL. Anesthesiologists with substance use disorders: a 5-year outcome study from 16 state physician health programs. Anesth Analg 2009; 109: 891-6.

20. DuPont RL, McLellan AT, White WL, Merlo LJ, Gold MS. Setting the standard for recovery: Physicians' Health Programs. J Subst Abuse Treat 2009; 36: 159-71. 
21. Farber NJ, Gilibert SG, Aboff BM, Collier VU, Weiner J, Boyer $E G$. Physicians' willingness to report impaired colleagues. Soc Sci Med 2005; 61: 1772-5.

22. Bryson EO, Silverstein JH. Addiction and substance abuse in anesthesiology. Anesthesiology 2008; 109: 905-17.

23. Earley $P H$. Persons in safety sensitive occupations. In: Mee-Lee D, Shulman GD, Fishman MJ, Gastfriend DR, Miller MM, Provence SM, editors. The ASAM Criteria: Treatment Criteria for Addictive, Substance-Related, and Co-Occurring Conditions. 3rd ed. Carson City, NV: The Change Companies; 2013. p. 340-9.

24. Hamza H, Bryson EO. Buprenorphine maintenance therapy in opioid-addicted health care professionals returning to clinical practice: a hidden controversy. Mayo Clin Proc 2012; 87: 260-7.

25. Newman $R G$. Buprenorphine maintenance therapy in opioidaddicted health care professionals. Mayo Clin Proc 2012; 87: 804-5; author reply 806-8.

26. Earley $P H$. Opioid substitution therapy for dependent health care practitioners: approach with caution. Mayo Clin Proc 2012; 87: 803-4; author reply 806-8.

27. Hulse GK, O'Neil G, Hatton M, Paech MJ. Use of oral and implantable naltrexone in the management of the opioid impaired physician. Anaesth Intensive Care 2003; 31: 196-201.

28. Jonas DE, Amick HR, Feltner C, et al. Pharmacotherapy for adults with alcohol use disorders in outpatient settings: a systematic review and meta-analysis. JAMA 2014; 311: 1889-900.
29. Domino KB, Hornbein TF, Polissar NL, et al. Risk factors for relapse in health care professionals with substance use disorders. JAMA 2005; 293: 1453-60.

30. Federation of State Physician Health Programs. Advocacy for members. Wilmington, MA: Federation of State Physician Health Programs; 2016. Available from URL: http://www.fsphp.org/ advocacy (accessed October 2016).

31. Brewster JM, Kaufmann IM, Hutchison S, MacWilliam C. Characteristics and outcomes of doctors in a substance dependence monitoring programme in Canada: prospective descriptive study. BMJ 2008; 337: a2098.

32. Somers JM, Rezansoff SN, Moniruzzaman A. Comparative analysis of recidivism outcomes following drug treatment court in Vancouver, Canada. Int J Offender Ther Comp Criminol 2014; 58: 655-71.

33. Skipper GE, DuPont RL. Anesthesiologists returning to work after substance abuse treatment. Anesthesiology 2009; 110: 14223 ; author reply $1426-8$.

34. Berge KH, Seppala MD, Lanier WL. The anesthesiology community's approach to opioid- and anesthetic-abusing personnel: time to change course. Anesthesiology 2008; 109: 762-4. 